\title{
A variational principle for a fractal nano/microelectromechanical system
}

\author{
Ji-huan $\mathrm{He}^{1}$ \\ ${ }^{1}$ Soochow University
}

August 13, 2020

\begin{abstract}
Wang's fractal variational principle for a fractal nano/microelectromechanical oscillator is studied(K.L. Wang. Mathematical Methods in the Applied Sciences, 2020, DOI: 10.1002/mma.6726), and its Euler-Lagrange equation is obtained. A new variational principle is obtained by the semi-inverse method.
\end{abstract}

\section{Hosted file}

fractal-MEMS-vp.docx available at https://authorea.com/users/299696/articles/475477-avariational-principle-for-a-fractal-nano-microelectromechanical-system 